Supporting Information

\title{
Air Stable Nanoporous Aluminum/Lithium Borohydride Fuel Pellets for Onboard Hydrogen Generation by Hydrolysis with Pure Water
}

\author{
Timothy Lee, ${ }^{\mathrm{a}}$ John S. Corsi,${ }^{\mathrm{a}, \mathrm{b}}$ Lin Wang, ${ }^{\mathrm{a}}$ and Eric Detsi ${ }^{\mathrm{a}, \mathrm{b}, *}$ \\ ${ }^{a}$ Department of Materials Science \& Engineering, University of Pennsylvania, Philadelphia PA 19104, USA \\ ${ }^{b}$ Vagelos Institute for Energy Science and Technology (VIEST), Philadelphia, PA 19104, USA. \\ *Email: detsi@seas.upenn.edu
}

Number of Pages: 4

Number of Videos: 2

Number of Figures: 1 

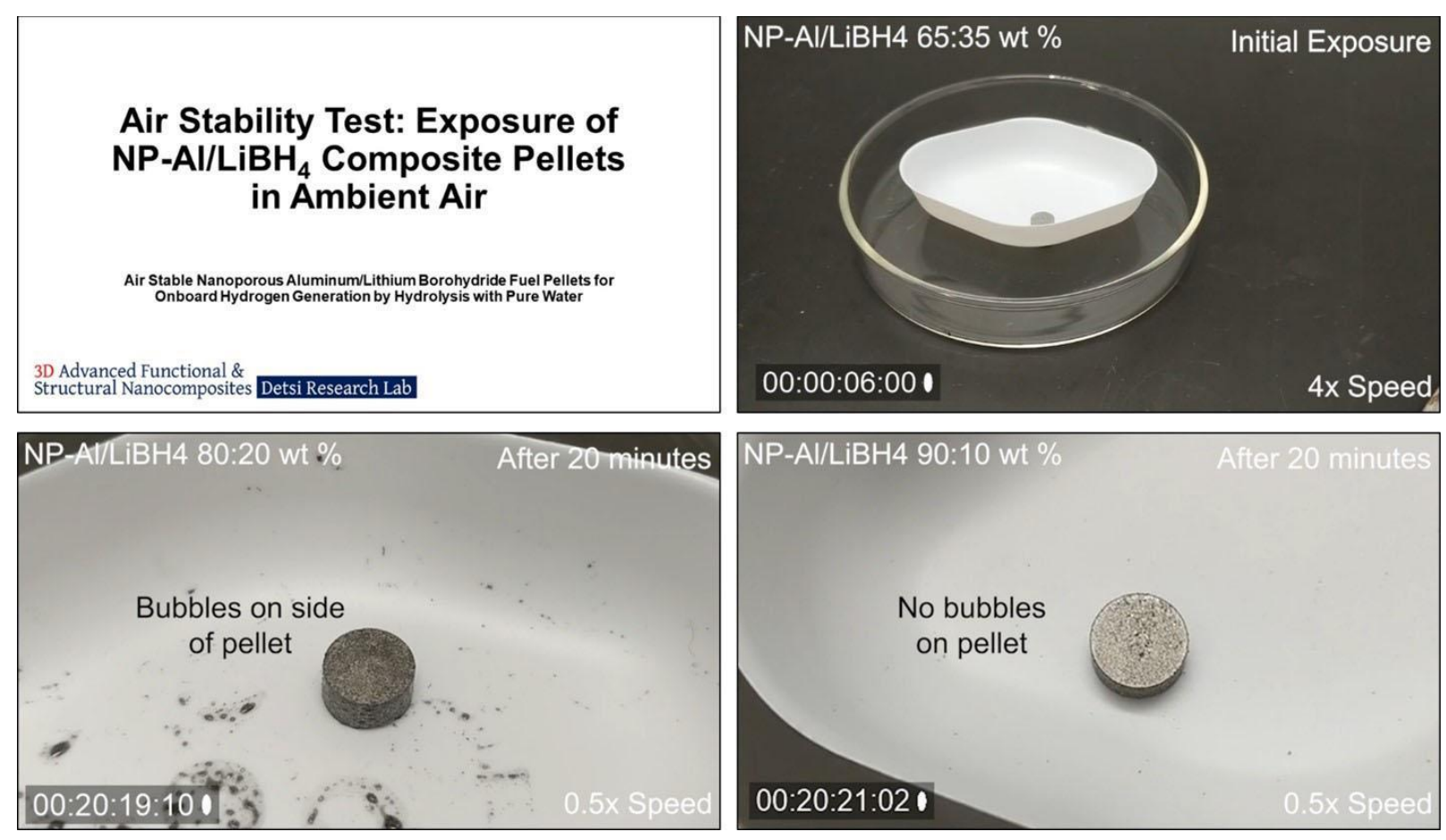

Supporting Video S1. Screenshots of air stability test: exposure of $\mathrm{NP}-\mathrm{Al} / \mathrm{LiBH}_{4}$ composite pellets in ambient air. 
Air Stability Test: Exposure of NP-Al/LiOH Composite Pellets in Ambient Air

Air Stable Nanoporous Aluminum/Lithium Borohydride Fuel Pellets for Onboard Hydrogen Generation by Hydrolysis with Pure Water

3D Advanced Functional \&
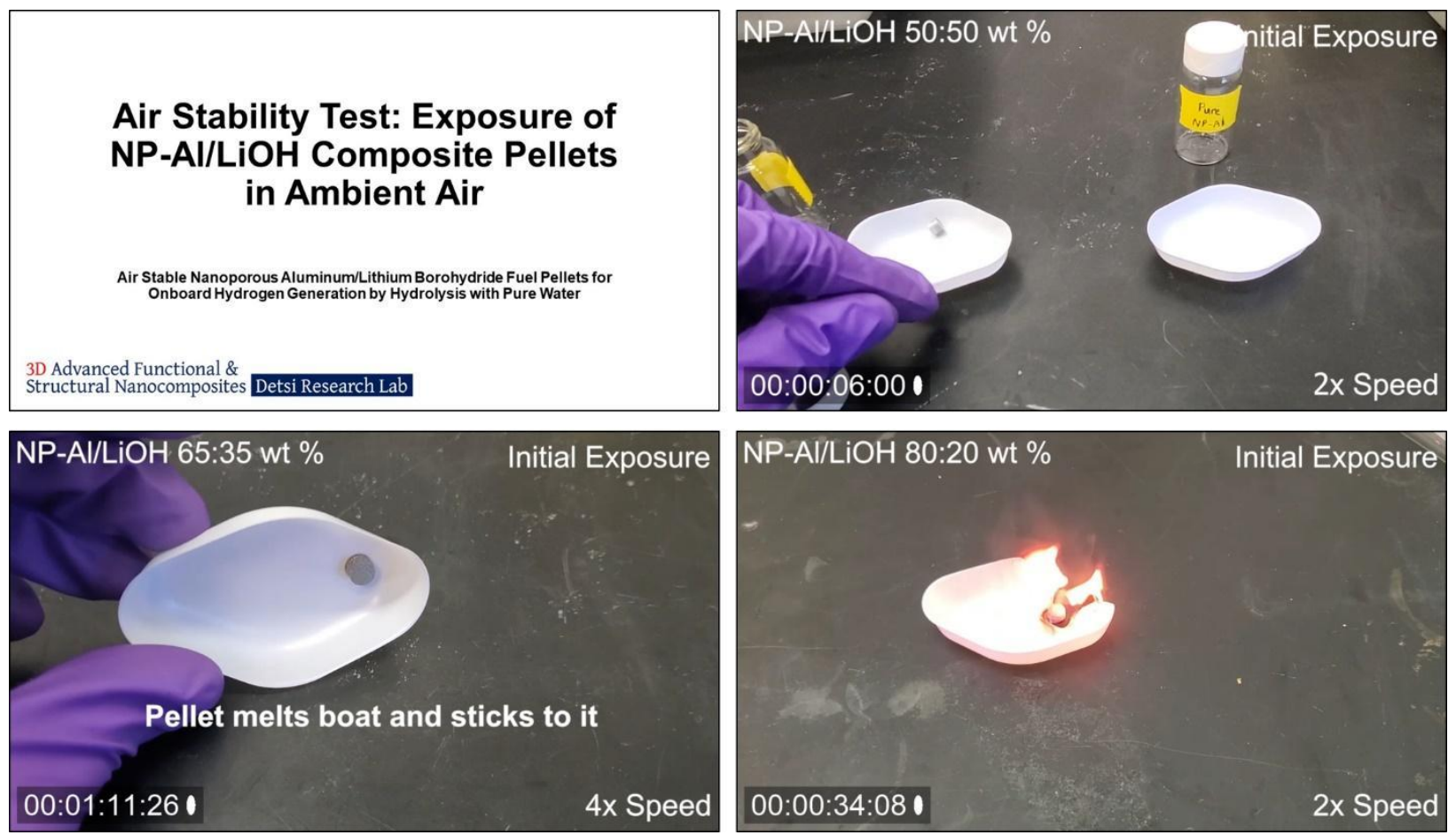

Supporting Video $\mathbf{S} 2$. Screenshots of air stability test: exposure of NP-Al/LiOH composite pellets and small pieces of NP-Al in ambient air. 


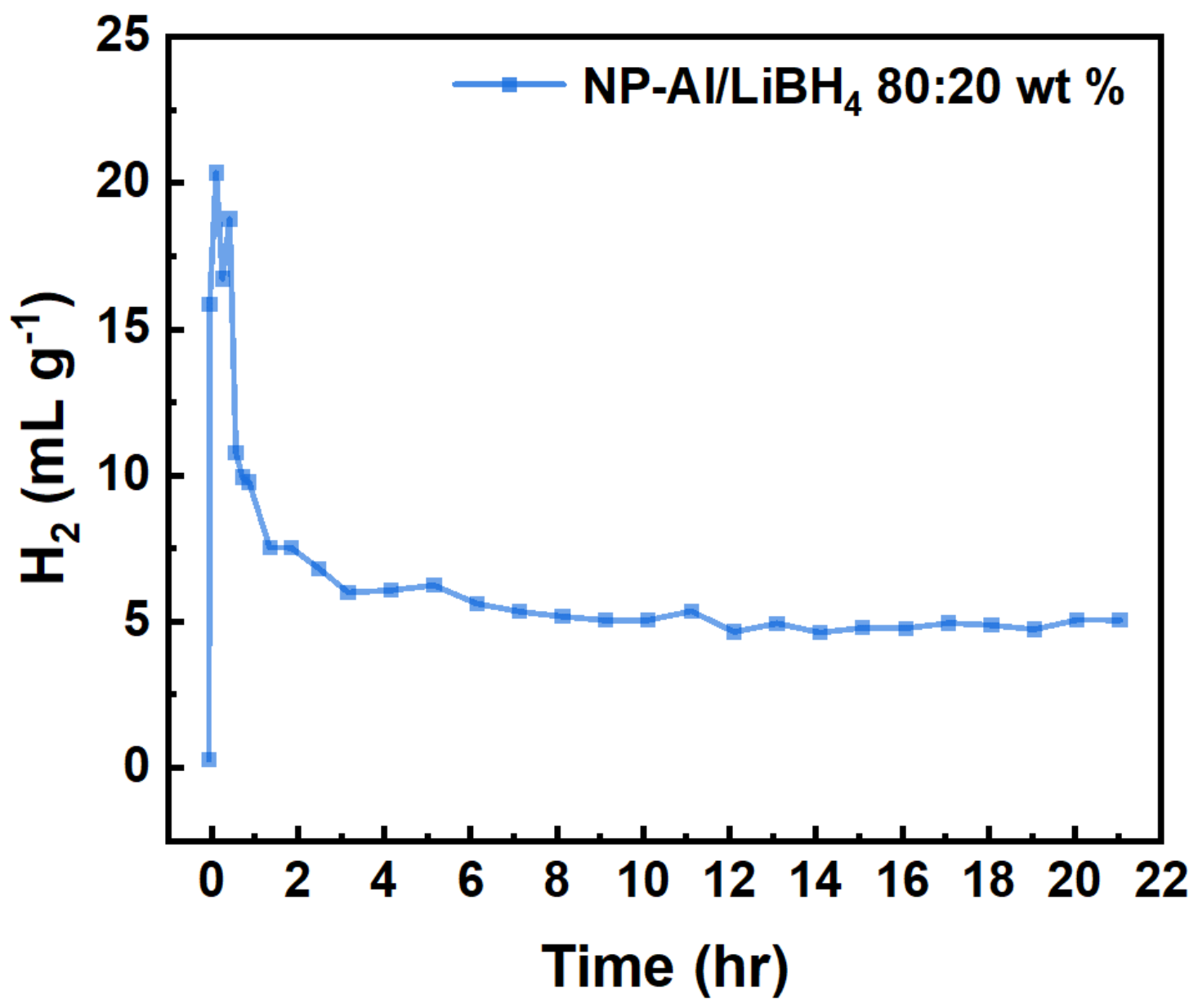

Figure S1. GC of NP-Al/LiBH $40: 20$ wt \% Composite Pellet over 22 hours. 